\title{
Human immunodeficiency virus type 1 (HIV-1)-mediated neuroinflammation dysregulates neurogranin and induces synaptodendritic injury
}

\author{
Debjani Guha, Marc C. E. Wagner and Velpandi Ayyavoo* (D)
}

\begin{abstract}
Background: Human immunodeficiency virus type 1 (HIV-1)-associated neurocognitive disorder (HAND) is a common outcome of a majority of HIV-1-infected subjects and is associated with synaptodendritic damage. Neurogranin ( $\mathrm{Ng}$ ), a postsynaptic protein, and calmodulin (CaM) are two important players of synaptic integrity/functions. The biological role of $\mathrm{Ng}$ in the context of HAND is unknown.

Methods: We compared the expression of $\mathrm{Ng}$ in frontal cortex (FC) tissues from control and HIV-1-positive subjects with and without HAND by immunohistochemistry, western blot, and qRT-PCR. The interaction between Ng and CaM was analyzed by co-immunoprecipitation. Ng, microtubule-associated protein 2 (MAP2), CaM, CaM-dependent protein kinase II (CaMKII), CREB, synaptophysin (Syp), and synapsin I (Syn I) expressions were evaluated by western blot using FC tissue lysates and differentiated SH-SY5Y (dSH-SY5Y) cells. Identification of inflammatory factors related to Ng loss was accomplished by exposing dSH-SY5Y cells to HIV-1 and mock-infected monocyte-derived macrophage (MDM) supernatants or HIV-1 NLYU2 pseudotyped with VSV-G-Env. Levels of interleukin (IL)-1 $\beta$, IL-8, tumor necrosis factor (TNF)-a, monocyte chemoattractant protein (MCP)-1, MCP-2, and CXCL5 in MDM supernatants were measured by ELISA. Association of IL-1 $\beta$ and IL-8 to Ng expression in context of HIV-1 infection was evaluated in the presence or absence of neutralizing antibodies against these cytokines.
\end{abstract}

Results: Expression level of $\mathrm{Ng}$ was reduced significantly in FC of HAND-positive (HAND+) patients compared to uninfected individuals. Although no difference was found in CaM expression, interaction between $\mathrm{Ng}$ and $\mathrm{CaM}$ was reduced in HAND+ patients, which was associated with decreased level of CaMKII, a downstream signaling molecule of CaM pathway. This in turn resulted in reduction of synaptic markers, Syp and Syn I. HIV-1 infection directly had no considerable effect on dysregulation of $\mathrm{Ng}$ expression in dSH-SY5Y cells, whereas high amount of pro-inflammatory IL-1 $\beta$ and IL-8 in HIV-1-infected MDM supernatants was associated with significant reduction in $\mathrm{Ng}$ expression.

Conclusions: Synaptic damage in HAND+ patients could be a result of abrogation of Ng through HIV-1-induced inflammation that dysregulates $\mathrm{Ng}$-CaM interaction and downstream signaling cascades associated with synaptodendritic functions. This is the first study evaluating the potential role of $\mathrm{Ng}$ in the context of HIV-1 neuropathogenesis.

Keywords: HIV-1, Neurogranin, Calmodulin, Frontal cortex, Synaptodendritic damage

\footnotetext{
* Correspondence: Velpandi@pitt.edu

Department of Infectious Diseases and Microbiology, Graduate School of

Public Health, University of Pittsburgh, 2117 Pitt Public Health, 130 DeSoto

Street, Pittsburgh, PA 15261, USA
}

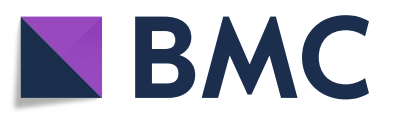

(c) The Author(s). 2018 Open Access This article is distributed under the terms of the Creative Commons Attribution 4.0 International License (http://creativecommons.org/licenses/by/4.0/), which permits unrestricted use, distribution, and reproduction in any medium, provided you give appropriate credit to the original author(s) and the source, provide a link to the Creative Commons license, and indicate if changes were made. The Creative Commons Public Domain Dedication waiver (http://creativecommons.org/publicdomain/zero/1.0/) applies to the data made available in this article, unless otherwise stated. 


\section{Background}

Prolonged life expectancy of HIV-1-positive subjects in the post-combination antiretroviral therapy (cART) era has persisted the neurocognitive problems and currently higher number of people are living with HIV-associated neurocognitive disorder (HAND). About 30-50\% of HIV1 -infected subjects suffer from mild to severe forms of neurocognitive abnormalities $[1,2]$. Synaptic disruption in addition to neuronal death is one of the underlying mechanisms of neurocognitive impairment in HIV-1-infected patients. In contrast with HIV-encephalitis (HIVE) and neuronal apoptosis, synaptodendritic injury due to HIV-1 infection is more directly related to cognitive impairments among HAND patients [3]. Multiple proteins are involved in synaptodendritic function, and calmodulin is one of the important regulators for synaptic integrity and regulates phosphorylation and activation of different synaptic proteins. For instance, formation of $\mathrm{Ca}^{2+}-\mathrm{CaM}$ complex is followed by activation of various isoforms of $\mathrm{Ca}^{2+} / \mathrm{CaM}-$ dependent protein kinase II (CaMKII), high concentration of which has been reported to be associated with the increased strength of synaptic plasticity [4]. Hence, dysregulation of calmodulin ( $\mathrm{CaM})$ pathway is likely to be involved in synaptic damage induced by HIV-1 infection.

Postsynaptic protein neurogranin $(\mathrm{Ng})$, mostly localized at the dendritic shafts and spines, is one of the regulatory factors for the availability of free $\mathrm{CaM} . \mathrm{Ng}$ binds to $\mathrm{Ca}^{2+}$-free $\mathrm{CaM}$ to form $\mathrm{Ng}$-CaM complex. However, the function of $\mathrm{Ng}-\mathrm{CaM}$ complex is not well defined. Previous studies have shown that $\mathrm{Ng}$ could either sequester $\mathrm{CaM}$ in the vicinity of its downstream effectors particularly CaMKII and thereby inhibit the activation of the target molecules or it could concentrate and/or target $\mathrm{CaM}$ within dendritic spines to facilitate $\mathrm{Ca}^{2+} / \mathrm{CaM}$-mediated signaling [5-8]. Studies have shown that $\mathrm{Ng}$ enhances calcium-mediated long-term potentiation (LTP) and transgenic mice lacking $\mathrm{Ng}$ results in impaired spatial learning tasks, and antibodies against $\mathrm{Ng}$ prevent LTP in hippocampal neurons in vitro $[9,10]$. Although the pivotal role of $\mathrm{Ng}$ in a number of neurological diseases (Alzheimer's disease, Parkinson's disease, stroke) has been demonstrated [11-14], very little is known about the mechanistic role of $\mathrm{Ng}$ in the context of HIV-1 infection and HAND. Here, we evaluated for the first time the expression and functional role of $\mathrm{Ng}$ in HIV-1-infected individuals with and without HAND.

The inflammatory nature of infected macrophages/ microglia in addition to HIV-1 viral proteins present in the central nervous system (CNS) are the major factors responsible for neuronal dysfunction [15-20]. Studies have demonstrated synaptic injury via exposure to viral proteins, Tat and gp120 [21, 22]. In addition, proinflammatory products released by HIV-1-infected macrophages have a role in synaptodendritic injury [3] supporting that HIV-1 impairs synaptic integrity. In this study, we delineated the mechanistic role of $\mathrm{Ng}$ in $\mathrm{HIV}$-1-induced synaptic damage through CaM-CaMKII signaling pathway. Our results suggest that HIV-1 infection significantly downregulates the expression of $\mathrm{Ng}$ at the advanced stage of HAND, i.e., HIV-1associated dementia (HAD). Furthermore, reduced $\mathrm{Ng}$ level results in loss of interaction with $\mathrm{CaM}$ leading to decreased expression of downstream protein CaMKII and synaptic markers Syp and Syn I. Additionally, proinflammatory cytokines, especially IL-1 $\beta$ and IL-8, caused significant reduction in $\mathrm{Ng}$ expression that could result in dysregulation of downstream CaM signaling molecules and disruption of the synapses. These observations, taken together, demonstrate that HIV-1induced inflammation in the CNS results in synaptic damage through $\mathrm{Ng}$ dysregulation.

\section{Methods}

Brain tissues from HIV-1-positive and control subjects

Age- and sex-matched human frontal cortex (FC) tissues (frozen tissues and formalin fixed slides) from eight HIV1-positive subjects with and without cognitive impairment and four HIV-1-negative subjects were obtained from National NeuroAIDS Tissue Consortium (NNTC) and multicenter AIDS cohort study (MACS) using appropriate IRB and CORID approval. Cognitive impairment included either HIV-1-associated dementia (HAD) or mild neurocognitive disorder (MND), and all of them were on cART. The demographic and clinical backgrounds of the study subjects are shown in Table 1.

\section{Virus preparation and characterization}

HIV-1 virus particles were generated using the pNL43YU2-Env EGFP (CCR5-receptor utilizing strain) proviral DNA constructs. HEK293T cells in $10-\mathrm{cm}$ plate were transfected with $5 \mu \mathrm{g}$ of HIV-1 proviral or vector DNA using polyjet reagent (SignaGen Laboratories, MD, USA) as per manufacturer's instructions. Supernatants were collected $72 \mathrm{~h}$ post-transfection, spun at $3000 \mathrm{rpm}$ for $10 \mathrm{~min}$, and filtered through a $0.4-\mu \mathrm{m}$ filter to remove cellular debris. All virus stocks were further concentrated by ultracentrifugation at 22,000 rpm for $1 \mathrm{~h}$ at $4{ }^{\circ} \mathrm{C}$ and were assessed for infectivity using TZM-bl assay. For infecting/exposing neuronal (differentiated SH-SY5Y) cells, HIV-1 NL-YU2 virus particles were pseudotyped with vesicular stomatitis virus envelope (VSV-G-Env).

\section{Infection of MDMs}

Monocytes were isolated from normal peripheral blood mononuclear cells (PBMC) and differentiated for 7 days. Briefly, CD $14^{+}$monocytes were purified from PBMC by positive selection using anti-CD14 monoclonal antibodycoated magnetic microbeads (Miltenyi Biotech) and differentiated in the presence of M-CSF and GM-CSF as 
Table 1 Demographic and clinical characteristics of study subjects

\begin{tabular}{|c|c|c|c|c|c|c|c|}
\hline Subjects & HIV status & Age (years) & Gender & HAND diagnosis & Plasma viral load (copies/ml) & 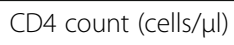 & ART \\
\hline 1 & Negative & 53 & Male & - & - & - & - \\
\hline 2 & Negative & 51 & Male & - & - & - & - \\
\hline 3 & Negative & 52 & Male & - & - & - & - \\
\hline 4 & Negative & 62 & Male & - & - & - & - \\
\hline 5 & Positive & 54 & Male & Normal & 113 & 18 & Yes \\
\hline 6 & Positive & 67 & Male & Normal & $<50$ & 347 & Yes \\
\hline 7 & Positive & 52 & Male & Normal & 82 & 317 & Yes \\
\hline 8 & Positive & 66 & Male & Normal & $<12$ & 465 & Yes \\
\hline 9 & Positive & 50 & Male & MND & NA & 24 & Yes \\
\hline 10 & Positive & 56 & Male & $\mathrm{HAD}$ & 452,705 & 8 & Yes \\
\hline 11 & Positive & 49 & Male & $\mathrm{HAD}$ & 246,267 & 13 & Yes \\
\hline 12 & Positive & 43 & Male & $\mathrm{HAD}$ & 201,702 & 56 & Yes \\
\hline
\end{tabular}

described previously [23]. MDMs were infected with a multiplicity of infection (MOI) of 0.5. Mock infection was performed using equal amount of HEK293T supernatant. MDM supernatants were collected 10 to 12 days post-infection.

\section{Differentiation of SH-SY5Y cells and exposure}

Neuroblastoma (SH-SY5Y) cells were cultured and differentiated into neuron as described by Dwane et al. (Dwane et al. BMC Research Notes 2013). In brief, SH-SY5Y cells were maintained in Dulbecco's modified Eagle's medium (DMEM) supplemented with $10 \%$ fetal bovine serum (FBS), $10 \mathrm{mM}$ L-glutamine, and $1 \%$ penicillin/streptomycin medium. For differentiation, cells were cultured in DMEM containing 3\% FBS and $10 \mu \mathrm{M}$ trans-retinoic acid (RA). Medium was changed every other day for 7 days. Post-differentiation, SH-SY5Y cells were either infected with neurotropic HIV-1 NLYU2 virus at an MOI of 1.0 for $72 \mathrm{~h}$ or exposed to mock or HIV-1-infected MDM supernatants for $24 \mathrm{~h}$. For exposure assays, MDMs were infected with R5 tropic HIV-1 NLYU2 at an MOI of 0.5 or mock for 10-12 days and supernatants from HIV-1 and mock-infected MDMs were used to expose differentiated SH-SY5Y cells (dSH-SY5Y) for 24 h. For neutralization assays, HIV-1infected MDM supernatants were incubated for $2 \mathrm{~h}$ with neutralizing antibody against IL- $1 \beta(5 \mu \mathrm{g} / \mathrm{ml})$ or IL-8 $(5 \mu \mathrm{g} / \mathrm{ml})$. dSH-SY5Y cells were exposed to HIV1-infected MDM supernatants containing neutralizing antibody and harvested $24 \mathrm{~h}$ post-exposure.

\section{Subcellular fractionation}

Separation and extraction of cytoplasmic and nuclear extracts from cells were performed using NE-PER nuclear and cytoplasmic extraction reagents according to manufacturer's protocol (Thermo Fisher). Briefly, control and dSH-SY5Y cells exposed to MDM supernatants were treated with ice-cold CER-I and CER-II reagents to extract the cytoplasmic fraction, and the nuclear fraction was extracted by NER reagent provided in the kit.

\section{Measurement of cytokines by ELISA}

Supernatants were collected from HIV-1- or mockinfected MDMs $(N=5)$ at 8 to 12 days post-infection and stored at $-80{ }^{\circ} \mathrm{C}$. Concentrations of TNF- $\alpha$, IL- $1 \beta$, IL-8, MCP-1, MCP-2, and CXCL5 in the HIV-1 and mock-infected supernatants were measured by ELISA following the manufacturer's protocol (R\&D Systems, Minneapolis, MN, USA).

\section{Immunohistochemistry (IHC)}

Human FC tissues along with formalin-fixed paraffinsectioned slides either from control or HIV-1-positive individuals with or without HAND were obtained from NNTC using appropriate institutional IRB and CORID approval. For IHC, samples went through a process of heating at $60{ }^{\circ} \mathrm{C}$ for approximately $14 \mathrm{~h}$. This was followed by deparaffinization involving several changes of xylene at 15 min each and succession of decreasing ethanol concentrations of 100,95 , and $70 \%$ then to distilled water. Slides were then subjected to heat-induced epitope retrieval (HIER) utilizing citrate buffer at $\mathrm{pH} 6.0$ in an electric pressure cooker at high heat for $15 \mathrm{~min}$ followed by a cooling down period prior to the initiation of IHC protocol. Tissues were treated with hydrogen peroxide to block endogenous peroxidase activity as part of 3rd Generation IHC Detection Kit (Invitrogen, CA). This was followed by blocking with $10 \%$ normal goat serum for 15 min prior to incubation with primary antibody. Anti-Ng antibody (EMD Millipore) was utilized at a 1:1000 dilution, and the tissue sections were incubated at $4{ }^{\circ} \mathrm{C}$ overnight. The slides were developed utilizing the same 3rd Generation IHC Detection Kit, dehydrated, and mounted using permount. 


\section{Immunofluorescence staining}

Treated and untreated dSH-SY5Y cells were fixed in 4\% paraformaldehyde for $15 \mathrm{~min}$ and permeabilized with 0 . 1\% Triton-X-PBS for $15 \mathrm{~min}$. The cells were rehydrated by three washes of PBS and five washes of $0.5 \%$ bovine serum albumin (BSA). After blocking with 2\% BSA for $1 \mathrm{~h}, \mathrm{dSH}-\mathrm{SY} 5 \mathrm{Y}$ cells were incubated with primary antibodies against $\mathrm{Ng}(1: 200)$ and microtubule-associated protein 2 (MAP2) (1:250) overnight at $4{ }^{\circ} \mathrm{C}$. Cells were washed five times with $0.5 \% \mathrm{BSA}$ and were further incubated with Alexa Flour 488 goat anti-mouse-IgG and anti-rabbit-Cy3 followed by five washes with $0.5 \%$ BSA with PBS, and the nuclei were stained with Hoechst $33342(1 \mu \mathrm{g} / \mathrm{ml})$. The slides were mounted, and images were taken using confocal microscope.

\section{Coimmunoprecipitation (Co-IP)}

Tissue lysates containing $100 \mu \mathrm{g}$ equivalent of protein were first pre-cleared with isotype control followed by incubation with $1 \mu \mathrm{g}$ of primary antibody at $4{ }^{\circ} \mathrm{C}$ for $60 \mathrm{~min}$ with gentle agitation. A/G plus agarose beads $(20 \mu \mathrm{l})$ were added and incubated for overnight at $4{ }^{\circ} \mathrm{C}$. The mixture was centrifuged at $3000 \mathrm{rpm}$ for $5 \mathrm{~min}$, and the supernatant was discarded. Antibody-bound protein complex was washed, and the pellet was suspended in a sample buffer for western blot.

\section{Western blot}

Differentiated SH-SY5Y cells (infected or exposed to MDM supernatants) were washed twice with cold PBS and lysed in buffer containing $50 \mathrm{mM}$ Tris ( $\mathrm{pH} 7.5), 150 \mathrm{mM} \mathrm{NaCl}$, $1 \%$ Triton X-100, $1 \mathrm{mM}$ sodium orthovanadate, $10 \mathrm{mM}$ sodium fluoride, $1 \mathrm{mM}$ phenylmethyl-sulfonylfluoride, $0.05 \%$ deoxycholate, 10\% SDS, 0.07 trypsin inhibitor units $/ \mathrm{ml}$ aprotinin, and protease inhibitors leupeptin, chymostatin, and pepstatin $(1 \mu \mathrm{g} / \mathrm{ml})$. About $5 \mathrm{mg}$ of frozen human FC tissues were cut into small pieces and homogenized in iceold RIPA buffer containing $1 \mathrm{mM}$ PMSF. Tissues were agitated in lysis buffer for $2 \mathrm{~h}$ at $4{ }^{\circ} \mathrm{C}$. Cells and tissue lysates were clarified by centrifugation at 10,000 rpm for $15 \mathrm{~min}$, and the total lysates $(30 \mu \mathrm{g}$ protein equivalent for cells and $5 \mu \mathrm{g}$ for tissues) were separated on a SDS-PAGE gel and transferred, and protein expression was detected with antiNg (EMD Millipore) (1:5000), anti-CaM (1:10000), antiCREB (1:1000), anti-CaMKII (1:1000), anti-synaptophysin (1:5000), and anti-BDNF (1:1000). Tubulin (Cell Signaling Technology) was used as the loading control. Blots were developed using the ECL kit (Pierce). Band intensity was quantitated by the Image software, and densitometry measurements were normalized against MAP2 or tubulin.

\section{Real-time PCR}

Total RNA was extracted from HIV-1-positive and HIV1-negative human FC tissues as well as from control, and treated dSH-SY5Y cells using the RNeasy mini kit according to the manufacturer's protocol (Qiagen, Valencia CA, USA). Quantitative real-time PCR was performed to determine the expression of $\mathrm{Ng}$ following manufacturer's protocol (Life Technologies) and normalized with MAP2 (neuronal marker) as control. Fold difference was calculated by $-\Delta \Delta$ Ct method.

\section{Statistical analysis}

In vivo data were analyzed by nonparametric MannWhitney test for non-normally distributed data using the GraphPad Prism software. In vitro data were analyzed by Student's $t$ test. Results were expressed as mean \pm SEM for at least three experiments, and $p<0.05$ was considered as significant. IHC pictures were analyzed using NIS Elements, and western blot band intensities were measured by the Image J software.

\section{Results}

Effect of HIV-1 infection and/or HAND on $\mathrm{Ng}$ expression

Earlier studies have implicated a role for $\mathrm{Ng}$ in brain diseases, such as Alzheimer's disease, Parkinson's disease, schizophrenia, epilepsy, and other neurodegenerative diseases; however, there is lack of understanding of the function of $\mathrm{Ng}$ in the context of HIV-1 infection or HAND. To determine whether $\mathrm{Ng}$ has any functional role in HAND pathogenesis, we analyzed FC tissues from eight HIV-1-infected subjects with and without cognitive impairment and four HIV-1-negative control subjects. Ng expression by $\mathrm{IHC}$ showed marked reduction of $\mathrm{Ng}$ level in HAND (+) subjects, compared to the control subjects. The major changes observed in HIV-1-positive FC tissues were the loss of dendrites as well as increased granularity of $\mathrm{Ng}$ (Fig. 1a). Quantitation of the expression of $\mathrm{Ng}$ in all three groups was determined by comparing mean area/cell and the mean intensity/cell. The mean area/cell was reduced significantly in both HIV-1-positive HAND $(-)(p=0.005)$ and HAND $(+)(p=0.004)$ patients compared to the uninfected control group (Fig. 1b). Mean intensity was significantly lower in HAND $(+)$ patients $(p=0.003)$; however, no significant difference was found in HAND (-) subjects compared to control subjects (Fig. 1c). IHC results were further confirmed by western blot using FC tissue lysates. The results were normalized with respect to another neuronal marker, MAP2 expression (Fig. 1d), which was normalized to tubulin. HAND (+) subjects exhibited reduced expression of $\mathrm{Ng}$ in the FC compared to uninfected control group ( $p=0.03$ ) (Fig. 1e). HIV-1-positive and cognitively normal subjects also showed similar trend of reduced $\mathrm{Ng}$ level compared to controls. Similar difference in control, HAND (-), and HAND (+) groups was also observed at the Ng RNA level (Fig. 1f) suggesting that HIV-1-induced downregulation of 

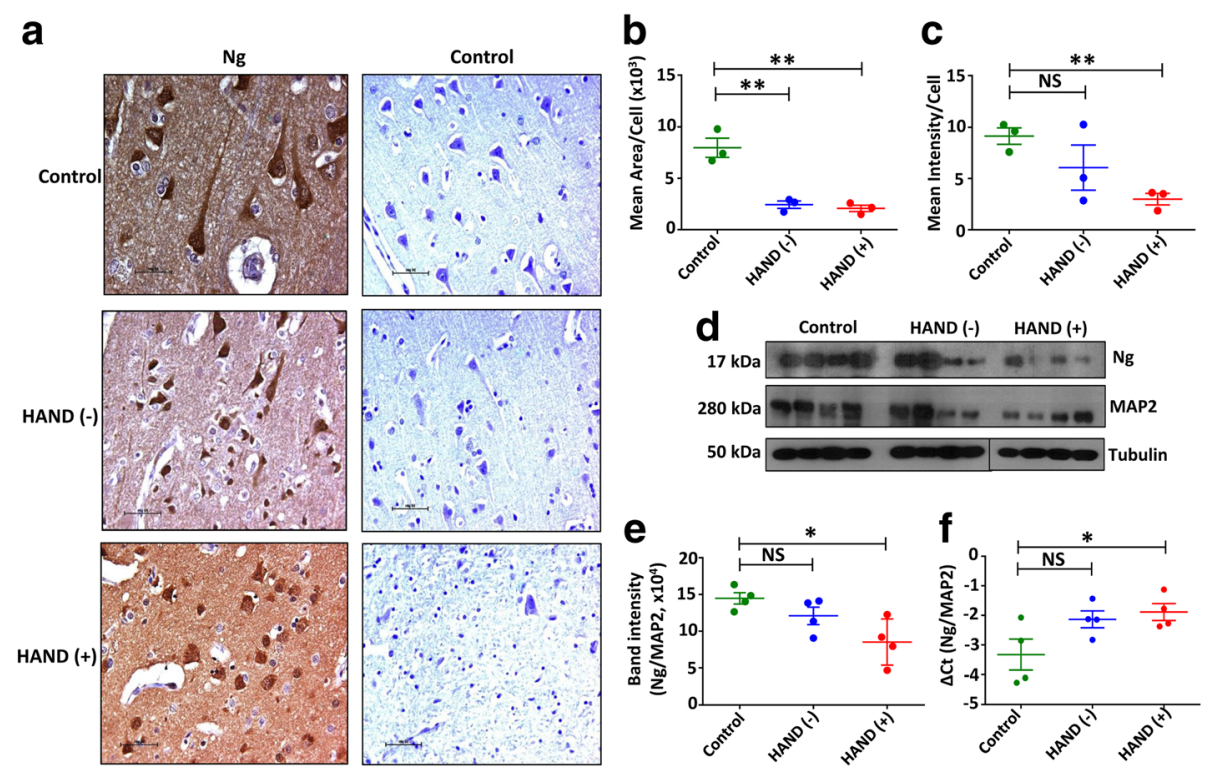

Fig. 1 HIV-1 infection and HAND pathology dysregulate Ng expression in human FC tissue: a FC sections from uninfected control, HAND (-), and HAND (+) subjects were IHC-stained for $\mathrm{Ng}$ and counterstained with hematoxylin. Scale bar indicates $50 \mu \mathrm{m}$. b, c The area and intensity of Ng-positive cells were counted from five different fields from each subject and divided by the total number of cells in those fields to calculate the mean area and mean intensity per cell. Positive cells were masked based on signal intensity threshold and normalized over noise using the NIS Elements software. Selection of an appropriate background and shading correction as well as smoothing filter object minimized noise of the images, allowing for more accurate analyses. d FC tissues from control, HAND (-), and HAND (+) subjects were homogenized and lysed, and 5 Hg of each lysate were loaded into each lane to measure $\mathrm{Ng}$ expression by western blot using specific antibody ( $\mathrm{N}=4$ for each group). MAP2 was used as control for normalization. Tubulin was used as a loading control. e Band intensities were quantitated by the ImageJ software, and the data were normalized with MAP2 and tubulin. $\mathbf{f}$ qRT-PCR was performed with $\mathrm{Ng}$-specific primers and probes using the RNA isolated from the frozen tissues from the same subjects ( $N=4$ for each group). Results were normalized with housekeeping gene RPLPO. Results are the \pm SEM of four individual experiments, nonparametric Mann-Whitney tests were performed to calculate significance, and ${ }^{*} p<0.05$ and ${ }^{* *} p<0.01$ compared to control. NS not significant

$\mathrm{Ng}$ expression might be regulated both at the RNA and protein level.

\section{HIV-1-induced reduction of $\mathrm{Ng}$ expression dysregulates CaM-CaMKII pathway}

$\mathrm{Ng}$ is known to interact with $\mathrm{CaM}$ and regulate the availability of $\mathrm{CaM}$ in the dendritic spines to induce synaptic plasticity $[7,8]$. Hence, to determine whether HIV-1 infection alters CaM level, we performed IHC on the uninfected control, HAND (-), and HAND (+) FC tissues. No significant difference in CaM expression was obtained in any of these groups (Fig. 2a, b). Next, we investigated by co-IP whether HIV-1-induced reduction of $\mathrm{Ng}$ concentration could result in alteration of $\mathrm{Ng}$ CaM interaction in HAND (-) or HAND (+) subjects. Briefly, FC tissue lysates from all three groups with equivalent amount of $\mathrm{CaM}$ were lysed and immunoprecipitated with anti-Ng antibody to pull down Ng-CaM complex followed by western blot using anti-CaM antibody. The average band intensity was compared among the groups and normalized against the control group. As presented in Fig. 2c, HAND (+) subjects exhibited significantly reduced interaction of $\mathrm{Ng}$ with $\mathrm{CaM}$ in comparison to the control group (0.366-fold compared to control, $p<0.05)$. Since CaMKII and CREB are known to strengthen synapses, we assessed whether reduced $\mathrm{Ng}-\mathrm{CaM}$ interaction in HAND (+) subjects results in alteration of the downstream molecules of the CaMCaMKII pathway. Tissue lysates from the three groups were used to perform western blot using anti-CaMKII and anti-CREB antibodies (Fig. 2d). MAP2 band intensities were first normalized with tubulin, and the intensities of CAMKII and CREB bands were normalized with MAP2. CaMKII expression was reduced by an average of 2.5 -fold $(p=0.0004)$ compared to control subjects and 1.8-fold $(p<0.05)$ compared to HAND $(-)$ subjects. A similar trend of reduction of CREB was also observed in HAND $(+)$ subjects compared to uninfected control subjects (Fig. 2e).

\section{HIV-1 infection induces synaptic damage in HAND- positive subjects}

Evaluation of synaptic dysfunction by measuring LTP with postmortem brain tissues was beyond our scope; hence, we selected two proteins, Syp and Syn I, that have potential roles in synaptic function such as synapse formation, biogenesis, synaptic transmission, and synaptic plasticity [24-26]. To assess the effect of HIV-1 infection on 

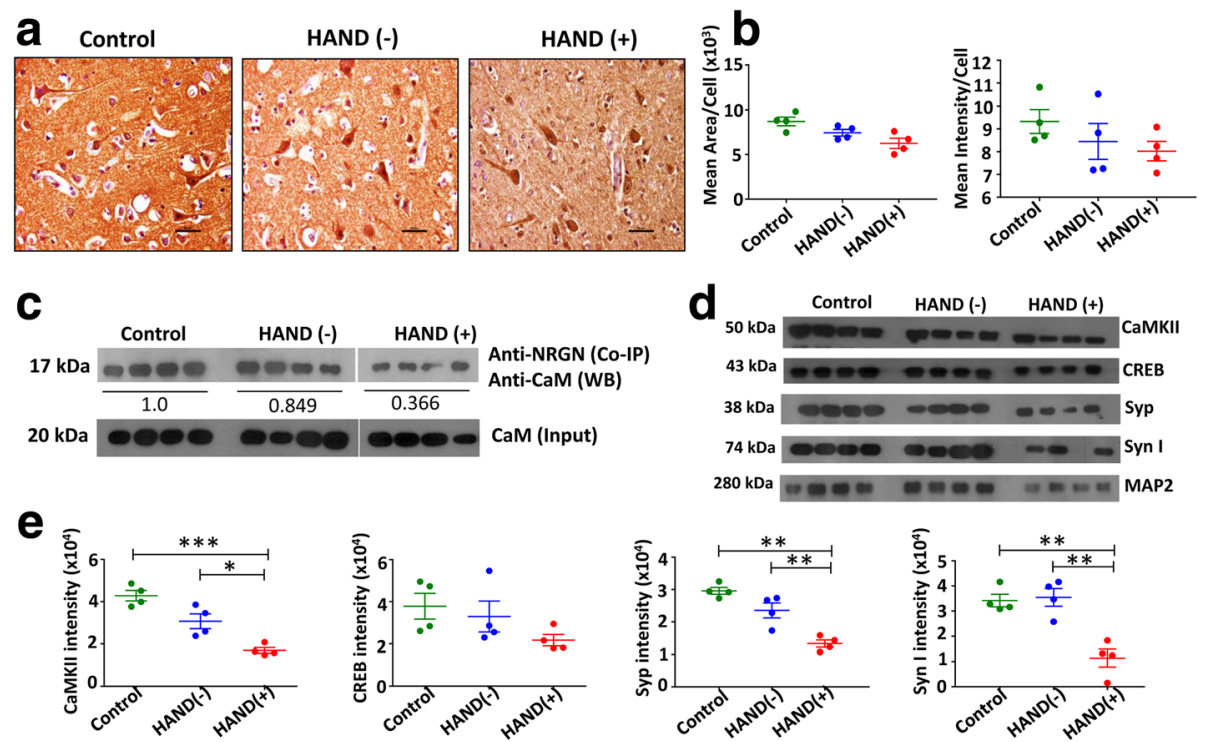

Fig. 2 Decreased Ng-CaM interaction reduces the expressions of synaptic plasticity markers in HAND patients. a IHC staining of CaM in the FC tissues from control, HAND (-), and HAND (+) subjects were performed. Scale bar indicates $50 \mu \mathrm{m}$. b Mean area/cell and mean intensity/cell were calculated from five different fields from each subject using the NIS Elements software. $\mathbf{c}$ Lysates prepared from control, HAND (-), and HAND (+) FC tissues were subjected to co-IP using anti-Ng antibody. Western blot was performed using anti-CaM antibody. Each lane represents sample from a single donor. Input represents presence of CaM in samples used for co-IP. $\mathbf{d}$ Control, HAND (-), and HAND (+) FC tissues were lysed, and $5 \mu \mathrm{g}$ of each lysate was analyzed by western blot using antibodies against CaMKII, CREB, Syp, Syn I, and MAP2. e Relative band intensities were normalized with MAP2. Densitometry quantification of western blot data represents \pm SEM of four independent observations. ${ }^{*} p<0.05$ compared to control. NS not significant

synaptic integrity and/or function, Syp and Syn I were analyzed by western blot in FC tissue samples along with CaMKII and CREB (Fig. 2d). Levels of both these proteins were decreased significantly in HAND $(+)$ subjects compared to control $(p=0.002$ for Syp and $p<0.0001$ for Syn I) and HAND (-) subjects ( $p=0.007$ for Syp and $p=0.003$ for Syn I) (Fig. 2e). No difference was found between HAND (-) and control subjects. Thus, these results suggest that HIV-1 infection and HAND pathogenesis alter the synaptic proteins through $\mathrm{Ng}$ dysregulation indicating synaptic dysfunction.

\section{HIV-1 infection indirectly dysregulates $\mathrm{Ng}$ expression in vitro}

Results described above indicate that HIV-1-positive subjects with HAND exhibit distinct $\mathrm{Ng}$ expression and related alterations of the downstream molecules associated with $\mathrm{Ng}$ pathway in vivo. Next, we sought to determine the factors responsible for the changes in Ng expression in the neurons. For this purpose, we used differentiated SH-SY5Y (dSH-SY5Y) cells. The neuronal phenotype of the differentiated cells was first confirmed by immunostaining (Fig. 3a) and western blot (Fig. 3b) using anti-MAP2 antibody. MAP2 positivity by immunofluorescence staining indicates $80 \%$ differentiation of SH-SY5Y cells. Interestingly, differentiated cells exhibited an increase in $\mathrm{Ng}$ expression compared to the undifferentiated cells. Hence, all the in vitro experiments were conducted using the dSH-SY5Ycells.
To further identify whether viral factors have a role in altering $\mathrm{Ng}$ expression, dSH-SY5Y cells were infected with either neurotropic HIV-1 NLYU2 virus pseudotyped with VSV-G at an MOI of 1 or mock for $72 \mathrm{~h}$. To assess the role of HIV-1-induced inflammatory factors in regulating $\mathrm{Ng}$ expression, MDMs were infected with $\mathrm{R} 5$ tropic HIV-1 NLYU2 at an MOI of 0.5 or mock for 10 12 days $(N=5)$. dSH-SY5Y cells were exposed to HIV-1 or mock-infected MDM supernatants for $24 \mathrm{~h}$, and the effect of HIV-1 infection and/or inflammatory factors on $\mathrm{Ng}$ expression was analyzed by western blot (Fig. 3c) and immunocytochemical staining (Fig. 3d). As expected, virus infection alone did not significantly affect $\mathrm{Ng}$ expression, whereas exposure to HIV-1-infected MDM supernatants decreased $\mathrm{Ng}$ level drastically in dSH-SY5Y cells compared to mock-infected MDM supernatant-exposed cells. Supernatants from mock-infected MDMs reduced the level of Ng expression by 1.8-fold, whereas supernatants from HIV-1-infected MDMs reduced the Ng expression by 4.7 -fold $(p<0.05)$. Analyses of immunostaining data showed that treatment of dSH-SY5Y cells with HIV1-infected MDM supernatants resulted in loss of Ng specifically from dendrites in addition to abrogation of the architecture of the cells. Together, these results suggest that excessive inflammation in HAND $(+)$ subjects could induce loss of $\mathrm{Ng}$. This could be either specific loss of $\mathrm{Ng}$ from dendrites or translocation of the same from dendrites to nucleus. To examine this, subcellular 

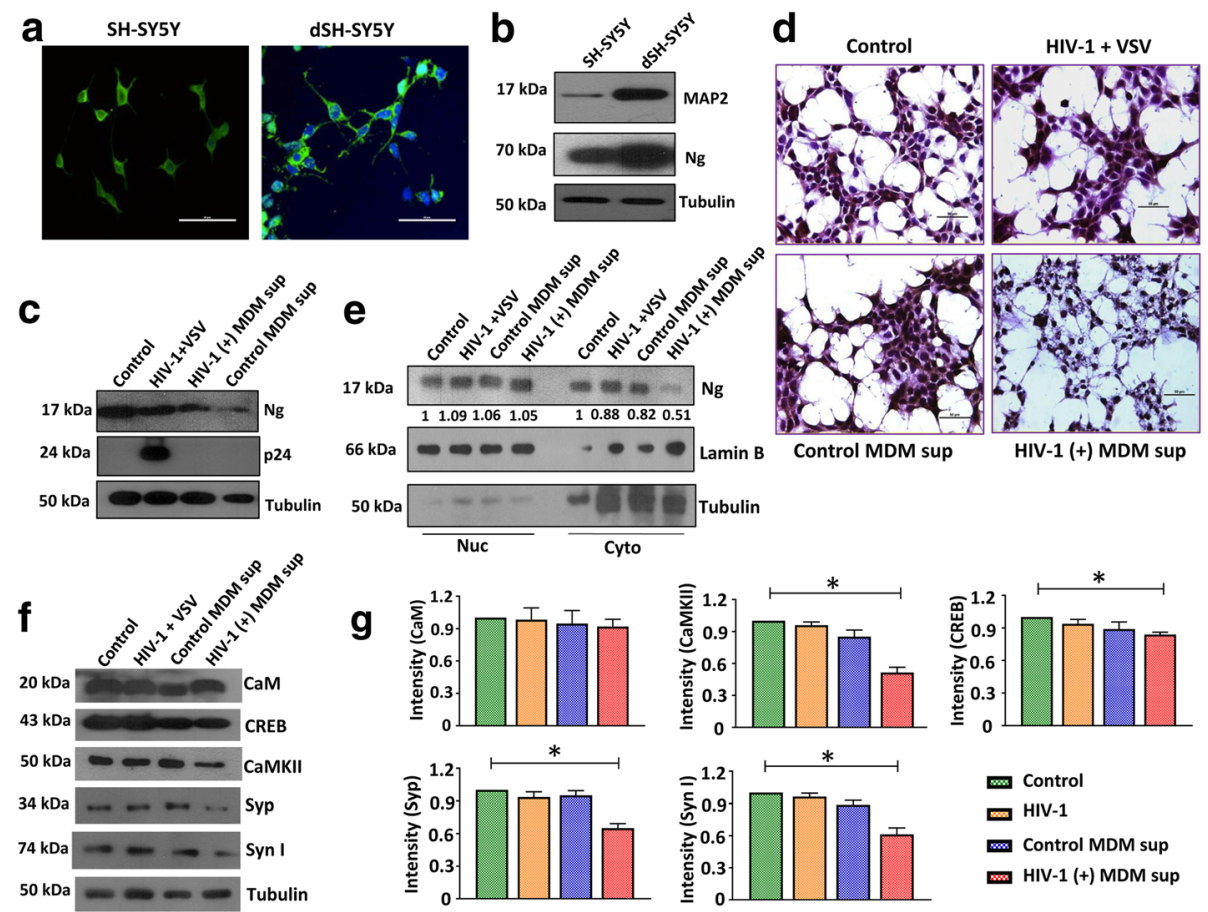

Fig. 3 Delineating the host cellular factors responsible for $\mathrm{Ng}$ deregulation. a Neuroblastoma cell line, SH-SY5Y cells were differentiated with RA and immunostained with MAP2-specific antibody. Green represents MAP2, and blue represents DAPI (nucleus). Ng expression increases post-differentiation of SH-SY5Y cells. Scale bar indicates $50 \mu \mathrm{m}$. b Differentiated (dSH-SY5Y) and undifferentiated SH-SY5Y cells were lysed and $30 \mu \mathrm{g}$ of protein was loaded, and expression of MAP2 and Ng was measured by western blot. Tubulin was used as a loading control. c dSH-SY5Y cells were either infected with HIV-1 NLYU2 pseudotyped with VSV-G at an MOI of 1.0 for $72 \mathrm{~h}$ or exposed to HIV-1 or mock-infected MDM supernatants for $24 \mathrm{~h}$. Expression of Ng in transduced or exposed cells was analyzed by western blot $(\mathrm{N}=3)$. $\mathbf{d}$ Control, transduced, or exposed dSH-SY5Y cells were stained for $\mathrm{Ng}$ and counterstained with hematoxylin. Scale bar represents $50 \mu \mathrm{m}$. e Cytoplasmic and nuclear fractions of the control, transduced, or exposed dSH-SY5Y cells were examined for the presence of $\mathrm{Ng}$ by western blot. Lamin B and tubulin were used as nuclear and cytoplasmic markers. Nuclear and cytoplasmic Ng band intensities were normalized over lamin B and tubulin, respectively. $\mathbf{f}$ Cell lysates from control, transduced, or exposed dSH-SY5Y cells $(30 \mu \mathrm{g})$ were examined for the expression of CaM, CaMKII, CREB, Syp, and Syn I by western blot. Tubulin was used as a loading control. $\mathbf{g}$ Relative band intensities were normalized with tubulin. Densitometry quantification of western blot data represents \pm SEM of three independent observations. ${ }^{*} p<0.05$ compared to control

fractionation was performed on control, HIV-1-infected, and MDM supernatant-exposed dSH-SY5Y cells and Ng expression was measured in both nuclear and cytoplasmic fractions. Lamin B and tubulin were used as markers for nuclear and cytoplasmic fractions, respectively. Nuclear and cytoplasmic Ng band intensities were normalized over lamin B and tubulin, respectively, and corrected for low level of contamination of other fractions. Following exposure of dSH-SY5Y cells to supernatants from HIV-1infected MDMs, no change in $\mathrm{Ng}$ in the nuclear fraction was observed, whereas there was about $50 \%$ reduction of $\mathrm{Ng}$ expression in the cytoplasmic fraction (Fig. 3e). This result indicates that the loss of $\mathrm{Ng}$ occurs primarily in the cytoplasm and/or dendrites of dSH-SY5Y cells.

Next, to investigate whether treatment of dSH-SY5Y cells with HIV-1 infected MDM supernatants could alter CaM-CaMKII pathway, expressions of CaM, CaMKII, and CREB were examined by western blot. No significant change was observed in CaM and CREB expression in $\mathrm{dSH}$-SY5Y cells exposed to HIV-1-infected MDM supernatant, whereas there was a significant $(p=0.03)$ reduction of CaMKII expression in exposed cells compared to the untreated control cells (Fig. 3f, g). Additionally, we also examined whether expression of the synaptic plasticity markers, Syp and Syn I, in dSH-SY5Y cells were altered post-exposure to the MDM supernatant or virus particles. Interestingly, it was noted that both Syp and Syn I expressions were reduced in dSHSY5Y cells treated with HIV-1-infected MDM supernatant by 4.5 - and 4.8 -fold, respectively, compared to that in control dSH-SY5Y cells (Fig. 3f, g). This suggests that inflammation due to HIV-1 infection could have a potential role in decreasing $\mathrm{Ng}$ expression and causing synaptic damage.

\section{Cellular factors responsible for HIV-1-induced dysregulation of $\mathrm{Ng}$ expression}

Both HIV-1 viral proteins and inflammatory cytokines have deleterious effect on neurons. However, studies have shown that viral proteins also trigger inflammation 
and upregulate inflammatory cytokines [22]. Hence, we focused on identifying the proinflammatory cytokines/ chemokines present in the HIV-1-infected MDM supernatants responsible for the alteration of $\mathrm{Ng}$ expression. For this purpose, we quantitated by ELISA the levels of cytokines/chemokines that are known to have roles in neuropathogenesis [23, 27-29]. Among the cytokines tested, we observed a significant increase in IL-1 $\beta(p=0$. $0005)$ and IL-8 $(p=0.0012)$ in HIV-1-infected MDM supernatants compared to mock-infected supernatants. No significant difference was found in the level of TNF- $\alpha$, MCP-1, MCP-2, and CXCL5 in those two groups (Fig. 4a).

To confirm that HIV-1-induced decreased expression of $\mathrm{Ng}$ is mediated at least in part through the proinflammatory cytokines released by infected MDMs, dSH-SY5Y cells were exposed to recombinant human IL- $1 \beta$ and IL- 8 for $48 \mathrm{~h}$. TNF- $\alpha$ was used as a control. Treatment of dSHSY5Y cells with rhIL-1 $\beta$ and rhIL-8 exhibited 4.1-fold $(p=0.003)$ and 6.3-fold $(p=0.002)$ reduction of $\mathrm{Ng}$ expression, respectively, (Fig. 4b), whereas no significant reduction in $\mathrm{Ng}$ expression was observed with TNF- $\alpha$ treatment. To further confirm the role of IL- $1 \beta$ and IL-8 in regulation of $\mathrm{Ng}$ expression, HIV-1-infected MDM supernatants were incubated with IL-1 $\beta$ and IL-8 neutralizing antibodies or isotype controls for $24 \mathrm{~h}$. dSH-SY5Y cells were exposed to the neutralizing antibody-treated MDM supernatants and $\mathrm{Ng}$ expression was determined by western blot. Exposure of dSHSY5Y cells to HIV-1-infected MDM supernatants with anti-IL-1 $\beta$ and anti-IL- 8 antibodies restored $69 \%$ and $73 \% \quad \mathrm{Ng}$ expression, respectively $(N=3)$ (Fig. 4c). Collectively, these results suggest that HIV-1-induced inflammation, specifically proinflammatory cytokines IL- $1 \beta$ and IL- 8 , have a potential role in Ng downregulation, which is associated with dysregulation of CaMCaMKII pathway and synaptic damage.

\section{Discussion}

Studies have established the role for $\mathrm{Ng}$ in $\mathrm{CNS}$ pathology, including Alzheimer's disease, Parkinson's disease, traumatic brain injury, and schizophrenia [30-34]. Ng functions as a potential biomarker for Alzheimer's
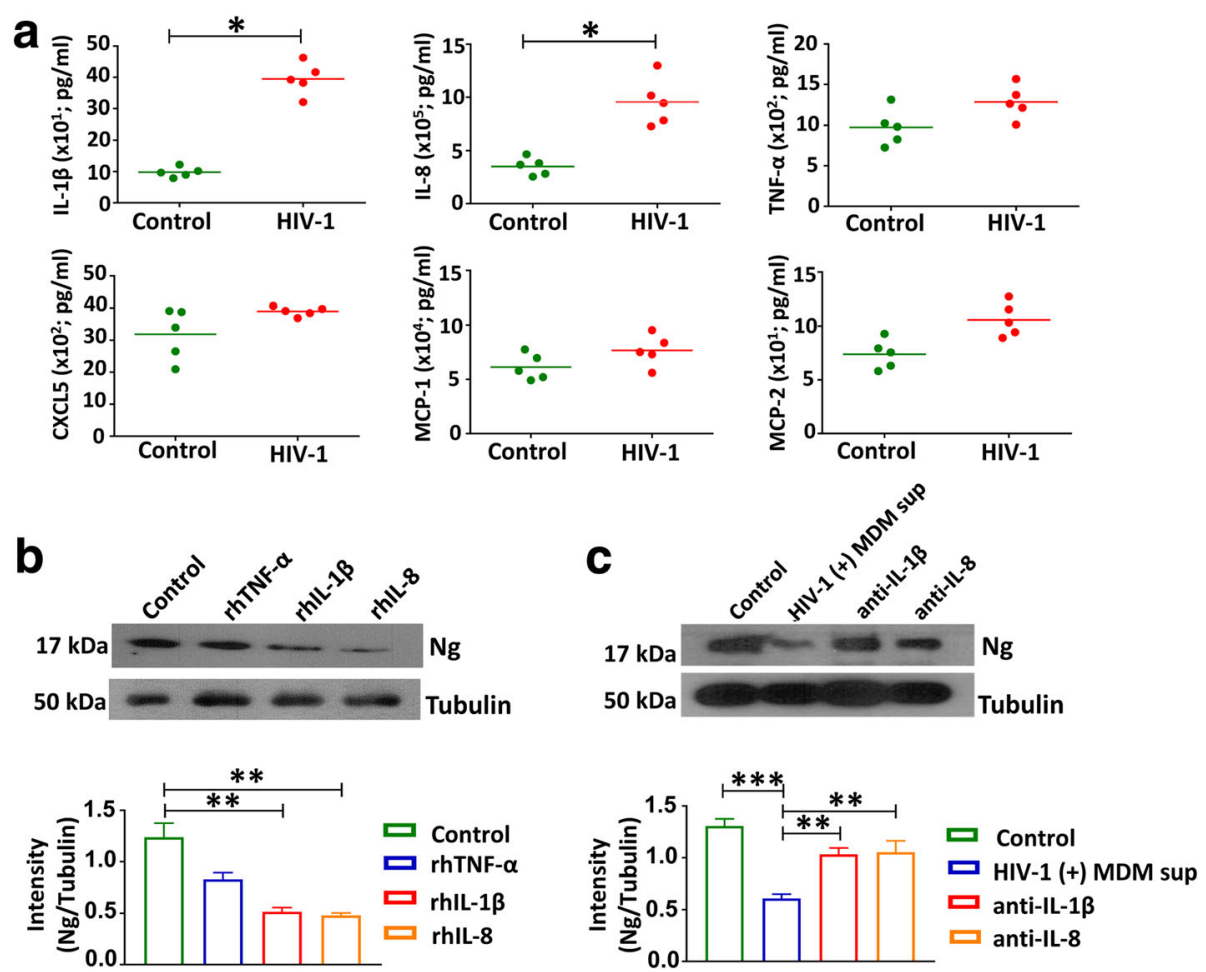

Fig. 4 Role of proinflammatory cytokines in Ng dysregulation: Normal donor-derived MDMs were infected with HIV-1 NLYU2 at an MOI of 0.5 or mock for 10-12 days. a Levels of IL-1 $\beta$, IL-8, TNF-a, CXCL5, MCP-1, and MCP-2 in supernatants of HIV-1 and mock-infected MDMs were measured by ELISA ( $N=5$ ). HIV-1 infection increased the production of proinflammatory cytokines. The horizontal lines represent mean concentrations of the cytokines. ${ }^{*} p<0.05$ compared to mock-infected cultures. $\mathbf{b}$ dSH-SY5Y cells were treated with rhlL-1 $\beta(10 \mathrm{ng} / \mathrm{ml})$, rhll-8 $(10 \mathrm{ng} / \mathrm{ml})$, and rhTNF-a $(100 \mathrm{ng} / \mathrm{ml})$ for $24 \mathrm{~h}$, and $30 \mu \mathrm{gg}$ of cell lysates for each sample was analyzed by western blot for $\mathrm{Ng}$. Tubulin was used as a loading control. Band intensities from three independent experiments were measured by the ImageJ software. c dSH-SY5Y cells were exposed to HIV-1-infected MDM supernatants with or without antiIL-1 $\beta$ or anti-IL-8 antibodies and harvested after $24 \mathrm{~h}$ of exposure. Cell lysates $(30 \mu \mathrm{g})$ were analyzed by western blot for $\mathrm{Ng}$. Band intensities from three independent experiments were measured by the ImageJ software. Densitometry quantification of western blot data represents \pm SEM of three independent observations. ${ }^{*} p<0.05$ and ${ }^{* *} p<0.01$ compared to control 
disease as higher level of $\mathrm{Ng}$ is consistently detected in the cerebrospinal fluid (CSF) of these patients $[35,36]$. Higher level of $\mathrm{Ng}$ in CSF is a correlate of cognitive decline in neurodegenerative diseases. However, not much is known regarding the role of HIV-1 infection on $\mathrm{Ng}$ expression or the correlate of Ng-HAND. Thus, to understand the significance of $\mathrm{Ng}$ in HIV-1-positive subjects with or without HAND, we used human FC tissues from HIV-1-positive and HIV-1-negative subjects. Most of the HAND (+) subjects were at the advanced stage of cognitive impairment (HAD). Although HAD accounts for only $3-7 \%$ of $H I V-1$ positive cases in the post-cART era, we included mostly HAD subjects to understand the ultimate changes in $\mathrm{Ng}$ expression in HIV-1-infected patients. Our goal was to determine the changes in $\mathrm{Ng}$ expression and associated downstream molecules at the advanced stage of the disease in HIV-1-positive subjects. We have shown that advanced pathology of HAND abrogates $\mathrm{Ng}$ expression in the FC tissues. In HAND (+) subjects, the pattern of $\mathrm{Ng}$ expression in FC tissues is very distinct compared to the normal individuals. Both distribution/localization and intensity of $\mathrm{Ng}$ are significantly reduced, and more importantly, extensive granularity of $\mathrm{Ng}$ is observed in HAND (+) subjects. To assess whether the decrease of $\mathrm{Ng}$ expression is a secondary effect of neuronal degeneration, we used a second neuronal marker, MAP2, which is present in the neuronal cell bodies and dendrites of both the brain and spinal cord [37]. Results upon normalization of Ng with MAP2 indicate that the effect of HIV-1 on Ng was independent of MAP2 modification, suggesting that dysregulation of $\mathrm{Ng}$ could modulate the downstream synaptic functions of neurons and it may not be a correlative effect.

The major function of $\mathrm{Ng}$ is to control the intracellular concentration of $\mathrm{CaM}$, which is essential for maintenance and function of synapses. In a recent study, it has been shown that increased $\mathrm{Ng}$ concentration enhances levels of $\mathrm{CaM}$ in the dendritic spines [38]. Thus, the level of $\mathrm{Ng}$ is one of the determining factors for CaM availability in the dendritic spines. Since the expression of $\mathrm{Ng}$ was reduced in HAND (+) subjects, we first sought to measure the concentration of CaM in uninfected, HIV-1-positive HAND (-), and HIV-1-positive HAND (+) groups. Surprisingly, following normalization with MAP2, no significant difference in the expression of CaM in any of the groups was noticed though reduction in dendritic length was observed in HAND $(+)$ patients. This could be due to the fact that the cellular concentration of CaM is very low and the availability could be regulated by a number of other calpacitin proteins in addition to $\mathrm{Ng}$. IHC or western blot may not be a very sensitive method to detect the small changes in $\mathrm{CaM}$ expression in $\mathrm{FC}$ tissues. Also, the expression of $\mathrm{CaM}$ is not similar in all regions of FC tissues; thus, screening more tissue sections of large number of FC samples may exemplify the significant reduction of CaM in HAND patients. However, due to the low availability of $\mathrm{Ng}$ in HAND (+) patients, there was a reduced $\mathrm{Ng}-\mathrm{CaM}$ interaction (the interaction between $\mathrm{Ng}$ and $\mathrm{CaM}$ could be direct or indirect), which could potentiate synaptic damage. With frozen postmortem human brain tissues, it was not possible to examine the inhibition of LTP using electrophysiological assays. Therefore, we assessed the expression level of synaptodendritic injury markers Syp and Syn I along with CaMKII and CREB. Results indicate that limited interaction of $\mathrm{Ng}$ with $\mathrm{CaM}$ resulted in downregulation of CaMKII molecule involved in the CaM-CaMKII pathway. CaMKII is implicated in synaptic plasticity, and activation of this molecule could invoke various nerve functions including neurotransmitter synthesis, release, ion channel and receptor function, learning, and memory [39]. It has also been reported that $\mathrm{Ng}$-mediated activation of CaMKII insert $\alpha$-amino-3-hydroxy-5-methyl-4-isoxazolepropionic acid receptors (AMPARs) at the synapses, which contributes to the induction of LTP [40]. Hence, downregulation of CaMKII could lead to failure in recruitment of AMPAR, impairment of synaptic plasticity, and other nerve functions. Downregulation of CaMKII in turn loses its potential to activate CREB, one of the downstream molecules of CaMKII pathway. Activation of CREB is important to induce multiple gene expression related to spatial memory formation [41] including brain-derived neurotrophic factor (BDNF), Syp, and Syn I. The latter two are synaptic vesicle-associated proteins involved in formation and maintenance of synapses [25, 42]. With the reduction in $\mathrm{Ng}$-CaM interaction, expressions of synaptodendritic markers were also reduced indicating synaptodendritic injury. Collectively, this suggests that $\mathrm{Ng}-\mathrm{CaM}$ interaction is one of the regulating factors for synaptodendritic integrity. These results correlate with a previous study, which reported that $\mathrm{Ng}$ mutants unable to bind to $\mathrm{CaM}$ do not potentiate synaptic transmission and knockdown of Ng blocks induction of LTP [43]. Similar results of reduced level of all the synaptodendritic markers were also found in our in vitro study with dSH-SY5Y cells exposed to HIV-1-infected MDM supernatants. However, it is also important to point out that differentiated SH-SY5Y cells do not form mature synapses, though they are morphologically similar to primary neurons and express neuron-specific markers including CaMKII, CREB, Syp, and Syn I.

Activated monocytes/macrophages are involved in trafficking the infectious HIV-1 through blood-brain barrier (BBB) into the brain compartment initiating the infection in the CNS. These cells release HIV-1 viral proteins and inflammatory molecules in the CNS and thus function as vital players for neuronal damage [44, 45]. HIV-1-infected macrophages/microglia have been shown to cause 
neuronal calcium dysregulation and neurotoxicity, the effects of which can be inhibited by blocking extracellular calcium signaling $[46,47]$. Thus, monocytes/macrophages are involved in maintenance as well as disruption of the molecular networks in the CNS. In this current study, we investigated whether HIV-1-infected MDMs have any role in causing Ng loss. Using HIV-1-infected MDM supernatants, we have shown that $\mathrm{Ng}$ was majorly abrogated from the cytoplasm of dSH-SY5Y cells, whereas the nuclear concentration of $\mathrm{Ng}$ did not show significant change. Whether this loss of $\mathrm{Ng}$ from the dendrites/cytoplasm is due to direct effect of the virus or an outcome of increased inflammation caused by viral infection is not well established.

The role of HIV-1 viral and cellular proteins in neuronal injury has been documented in multiple studies. Among the viral proteins, gp120 and Tat are more common to exert a functional role in disrupting neuronal plasticity [48]. HIV-1 Tat overexpresses histone deactylase 2 (HDAC2) in neuronal cells that results in downregulation of CaMKII and CREB leading to impaired synaptic plasticity [49]. On the other hand, release of these viral proteins disrupts the $\mathrm{BBB}$ leading to infiltration of more HIV-1-infected monocytes into the CNS. These infected cells in turn produce more viral proteins, inflammatory cytokines, and neurotoxins, which may be the major factors causing disruption of neuronal damage. HIV-1-associated inflammation has marked effects on HAND pathology. Neuroinflammation makes the dendrites and synapses more susceptible to excitotoxic injury [50]. The proinflammatory cytokines/chemokines produced excessively in the brain during chronic inflammation including tumor necrosis factor (TNF)- $\alpha$, IL$1 \beta$, and IL- 8 have profound effects on synaptic transmission and plasticity [51, 52]. Elevated levels of TNF- $\alpha$ during chronic inflammation modulate synaptic signaling through activation of TNFR1 receptors on pre- and post-synaptic neurons [53-55]. Elevated levels of IL-1 $\beta$ and IL-8 secreted by brain macrophages in the HIVE patients inhibit the induction of LTP [56, 57]. We focused on the roles of host inflammatory factors, because studies have shown that viral toxicity is induced by inflammatory host-derived cofactors [58] and also viral proteins such as gp120 causes neuronal damage through upregulating inflammatory cytokines [22]. We have shown for the first time that in HIV-1-infected subjects, inflammatory IL- $1 \beta$ and IL- 8 levels are associated with $\mathrm{Ng}$ downregulation and synaptodendritic injury. In contrast to other studies, TNF- $\alpha$ level was not significantly $(p=0.0625)$ elevated in HIV-1-infected MDMs compared to controls, although similar trend was observed. One possible explanation could be the difference in time of collection of MDM supernatants after infection or MOI used for infection. Treatment of dSH-SY5Y cells with HIV-1infected MDM supernatants markedly reduced $\mathrm{Ng}$ as well as CaMKII and synaptic markers Syp and Syn I. Treatment with recombinant proteins and neutralizing antibodies further confirmed our results. Together, chronic HIV-1 infection alters the inflammatory milieu in the CNS compartment leading to downregulation of $\mathrm{Ng}$, which is associated with at least in part with the synaptodendritic injury.

\section{Conclusion}

This is the first study evaluating the expression and functional role of $\mathrm{Ng}$ in the context of HIV-1 neuropathogenesis. Here, we demonstrate that HIV-1 infection decreases the level of $\mathrm{Ng}$ in human FC tissues in HAD patients and this decrease is in part due to overexpression of proinflammatory cytokines IL- $1 \beta$ and IL- 8 . The reduced expression of $\mathrm{Ng}$ in $\mathrm{HAD}$ subjects results in a limited interaction with $\mathrm{CaM}$ in the dendritic spines that dysregulates the downstream CaM-CaMKII signaling pathway. This in turn abrogates the synaptic plasticity measured by the reduced expression of Syp and Syn I. These results demonstrate one of the mechanisms of cognitive impairment in HAD-positive subjects through $\mathrm{Ng}$ dysregulation.

\section{Acknowledgements}

We would like to thank National NeuroAIDS Tissue Consortium and Multicenter AIDS cohort study for supplying the human brain tissue samples. We thank Dr. Simon Watkin's imaging facility for their help with the imaging analyses.

\section{Funding}

This work was supported in part by R01 MH087247 to VA from NIH. The samples used in this manuscript were collected by the Multicenter AIDS Cohort Study (MACS) with support from an American Recovery and Reinvestment Act (ARRA) supplement with centers (Principal Investigators) at Johns Hopkins University Bloomberg School of Public Health (Joseph Margolick), U01-Al35042; Northwestern University (Steven Wolinsky), U01-Al35039; University of California, Los Angeles (Roger Detels, Otoniel Martinez-Maza), U01-Al35040; University of Pittsburgh (Charles Rinaldo), U01-Al35041; and the Center for Analysis and Management of MACS, Johns Hopkins University Bloomberg School of Public Health (Lisa Jacobson), UM1-AI35043. The MACS is funded primarily by the National Institute of Allergy and Infectious Diseases (NIAID), with an additional co-funding from the National Cancer Institute (NCI). The contents of this publication are solely the responsibility of the authors and do not represent the official views of the National Institutes of Health $(\mathrm{NIH})$, Johns Hopkins ICTR, or NCATS. The MACS website is located at http://aidscohortstudy.org. DG was partially supported by Fogarty training grant D43TW010039.

\section{Authors' contributions}

DG and VA designed the experiments and wrote the manuscript. DG and MW performed the experiments and analyzed the data. All authors read and approved the final manuscript.

Ethics approval and consent to participate

FC tissues and formalin-fixed paraffin-sectioned slides were obtained from NNTC and CAMACS using appropriate institutional IRB and CORID approval.

\section{Consent for publication}

Agree to publish as required by the funding agency $(\mathrm{NIH})$. The subjects enrolled in MACS and NNTC consent to publish results utilizing the samples/ specimen provided by them for the research study.

Competing interests

The authors declare that they have no competing interests. 


\section{Publisher's Note}

Springer Nature remains neutral with regard to jurisdictional claims in published maps and institutional affiliations.

Received: 26 January 2018 Accepted: 13 April 2018

Published online: 27 April 2018

\section{References}

1. Woods SP, Moore DJ, Weber E, Grant I. Cognitive neuropsychology of HIVassociated neurocognitive disorders. Neuropsychol Rev. 2009;19:152-68.

2. Heaton RK, Clifford DB, Franklin DR Jr, Woods SP, Ake C, Vaida F, Ellis RJ, Letendre SL, Marcotte TD, Atkinson JH, et al. HIV-associated neurocognitive disorders persist in the era of potent antiretroviral therapy: CHARTER study. Neurology. 2010;75:2087-96.

3. Everall IP, Heaton RK, Marcotte TD, Ellis RJ, McCutchan JA, Atkinson JH Grant I, Mallory M, Masliah E. Cortical synaptic density is reduced in mild to moderate human immunodeficiency virus neurocognitive disorder. HNRC group. HIV Neurobehavioral Research Center. Brain Pathol. 1999;9:209-17.

4. Xia Z, Storm DR. The role of calmodulin as a signal integrator for synaptic plasticity. Nat Rev Neurosci. 2005;6:267-76.

5. Krucker T, Siggins GR, McNamara RK, Lindsley KA, Dao A, Allison DW, De Lecea L, Lovenberg TW, Sutcliffe JG, Gerendasy DD. Targeted disruption of RC3 reveals a calmodulin-based mechanism for regulating metaplasticity in the hippocampus. J Neurosci. 2002;22:5525-35.

6. Prichard L, Deloulme JC, Storm DR. Interactions between neurogranin and calmodulin in vivo. J Biol Chem. 1999;274:7689-94.

7. Zhabotinsky AM, Camp RN, Epstein IR, Lisman JE. Role of the neurogranin concentrated in spines in the induction of long-term potentiation. $J$ Neurosci. 2006;26:7337-47.

8. Diez-Guerra FJ. Neurogranin, a link between calcium/calmodulin and protein kinase C signaling in synaptic plasticity. IUBMB Life. 2010;62:597-606.

9. Fedorov NB, Pasinelli P, Oestreicher AB, DeGraan PN, Reymann KG. Antibodies to postsynaptic PKC substrate neurogranin prevent long-term potentiation in hippocampal CA1 neurons. Eur J Neurosci. 1995;7:819-22.

10. Huang KP, Huang FL, Jager T, Li J, Reymann KG, Balschun D. Neurogranin/ RC3 enhances long-term potentiation and learning by promoting calciummediated signaling. J Neurosci. 2004:24:10660-9.

11. Thorsell A, Bjerke M, Gobom J, Brunhage E, Vanmechelen E, Andreasen N, Hansson O, Minthon L, Zetterberg H, Blennow K. Neurogranin in cerebrospinal fluid as a marker of synaptic degeneration in Alzheimer's disease. Brain Res. 2010;1362:13-22

12. Lista S, Toschi N, Baldacci F, Zetterberg H, Blennow K, Kilimann I, Teipel SJ, Cavedo E, Dos Santos AM, Epelbaum S, et al. Cerebrospinal fluid neurogranin as a biomarker of neurodegenerative diseases: a cross-sectional study. J Alzheimers Dis. 2017;59:1327-34.

13. Bereczki E, Bogstedt A, Hoglund K, Tsitsi P, Brodin L, Ballard C, Svenningsson $P$, Aarsland D. Synaptic proteins in CSF relate to Parkinson's disease stage markers. NPJ Parkinsons Dis. 2017:3:7.

14. De Vos A, Bjerke M, Brouns R, De Roeck N, Jacobs D, Van den Abbeele L, Guldolf K, Zetterberg H, Blennow K, Engelborghs S, Vanmechelen E. Neurogranin and tau in cerebrospinal fluid and plasma of patients with acute ischemic stroke. BMC Neurol. 2017;17:170.

15. Genis P, Jett M, Bernton EW, Boyle T, Gelbard HA, Dzenko K, Keane RW, Resnick L, Mizrachi Y, Volsky DJ, et al. Cytokines and arachidonic metabolites produced during human immunodeficiency virus (HIV)-infected macrophage-astroglia interactions: implications for the neuropathogenesis of HIV disease. J Exp Med. 1992;176:1703-18.

16. Mordelet E, Kissa K, Cressant A, Gray F, Ozden S, Vidal C, Charneau P, Granon S. Histopathological and cognitive defects induced by Nef in the brain. FASEB J. 2004;18:1851-61.

17. Nath A. Pathobiology of human immunodeficiency virus dementia. Semin Neurol. 1999;19:113-27.

18. Nath A, Haughey NJ, Jones M, Anderson C, Bell JE, Geiger JD. Synergistic neurotoxicity by human immunodeficiency virus proteins Tat and gp120: protection by memantine. Ann Neurol. 2000;47:186-94.

19. Perez A, Probert AW, Wang KK, Sharmeen L. Evaluation of HIV-1 Tat induced neurotoxicity in rat cortical cell culture. J Neurovirol. 2001;7:1-10.

20. Yoshioka M, Bradley WG, Shapshak P, Nagano I, Stewart RV, Xin KQ, Srivastava AK, Nakamura S. Role of immune activation and cytokine expression in HIV-1-associated neurologic diseases. Adv Neuroimmunol. 1995;5:335-58.
21. Hargus NJ, Thayer SA. Human immunodeficiency virus-1 Tat protein increases the number of inhibitory synapses between hippocampal neurons in culture. J Neurosci. 2013;33:17908-20

22. Festa L, Gutoskey CJ, Graziano A, Waterhouse BD, Meucci O. Induction of interleukin-1 beta by human immunodeficiency virus-1 viral proteins leads to increased levels of neuronal ferritin heavy chain, synaptic injury, and deficits in flexible attention. J Neurosci. 2015;35:10550-61.

23. Guha D, Nagilla P, Redinger C, Srinivasan A, Schatten GP, Ayyavoo V. Neuronal apoptosis by HIV-1 Vpr: contribution of proinflammatory molecular networks from infected target cells. J Neuroinflammation. 2012;9:138.

24. Spiwoks-Becker I, Vollrath L, Seeliger MW, Jaissle G, Eshkind LG, Leube RE. Synaptic vesicle alterations in rod photoreceptors of synaptophysindeficient mice. Neuroscience. 2001;107:127-42.

25. Tarsa L, Goda Y. Synaptophysin regulates activity-dependent synapse formation in cultured hippocampal neurons. Proc Natl Acad Sci U S A. 2002:99:1012-6.

26. Thiele C, Hannah MJ, Fahrenholz F, Huttner WB. Cholesterol binds to synaptophysin and is required for biogenesis of synaptic vesicles. Nat Cell Biol. 2000;2:42-9.

27. Mayne M, Bratanich AC, Chen P, Rana F, Nath A, Power C. HIV-1 tat molecular diversity and induction of TNF-alpha: implications for HIV-induced neurological disease. Neuroimmunomodulation. 1998:5:184-92.

28. El-Hage N, Wu G, Ambati J, Bruce-Keller AJ, Knapp PE, Hauser KF. CCR2 mediates increases in glial activation caused by exposure to HIV-1 Tat and opiates. J Neuroimmunol. 2006;178:9-16.

29. Guha D, Klamar CR, Reinhart T, Ayyavoo V. Transcriptional regulation of CXCL5 in HIV-1-infected macrophages and its functional consequences on CNS pathology. J Interf Cytokine Res. 2015;35:373-84.

30. Tarawneh R, D'Angelo G, Crimmins D, Herries E, Griest T, Fagan AM, Zipfel GJ, Ladenson JH, Morris JC, Holtzman DM. Diagnostic and prognostic utility of the synaptic marker neurogranin in Alzheimer disease. JAMA Neurol. 2016;73:561-71.

31. Portelius E, Zetterberg $H$, Skillback T, Tornqvist U, Andreasson U, Trojanowski $J Q$, Weiner MW, Shaw LM, Mattsson N, Blennow K, Alzheimer's Disease Neuroimaging I. Cerebrospinal fluid neurogranin: relation to cognition and neurodegeneration in Alzheimer's disease. Brain. 2015;138:3373-85.

32. Yang J, Korley FK, Dai M, Everett AD. Serum neurogranin measurement as a biomarker of acute traumatic brain injury. Clin Biochem. 2015;48:843-8.

33. Koob AO, Shaked GM, Bender A, Bisquertt A, Rockenstein E, Masliah E. Neurogranin binds alpha-synuclein in the human superior temporal cortex and interaction is decreased in Parkinson's disease. Brain Res. 2014;1591:102-10.

34. Shen YC, Tsai HM, Cheng MC, Hsu SH, Chen SF, Chen CH. Genetic and functional analysis of the gene encoding neurogranin in schizophrenia. Schizophr Res. 2012;137:7-13.

35. Fyfe I. Alzheimer disease: neurogranin in the CSF signals early Alzheimer disease and predicts disease progression. Nat Rev Neurol. 2015:11:609.

36. Wellington $\mathrm{H}$, Paterson RW, Portelius E, Tornqvist U, Magdalinou N, Fox NC, Blennow K, Schott JM, Zetterberg H. Increased CSF neurogranin concentration is specific to Alzheimer disease. Neurology. 2016;86:829-35.

37. Li GL, Farooque M, Lewen A, Lennmyr F, Holtz A, Olsson Y. MAP2 and neurogranin as markers for dendritic lesions in CNS injury. An immunohistochemical study in the rat. APMIS. 2000;108:98-106.

38. Petersen A, Gerges NZ. Neurogranin regulates CaM dynamics at dendritic spines. Sci Rep. 2015:5:11135.

39. Yamauchi T. Neuronal Ca2+/calmodulin-dependent protein kinase $\|$ - discovery, progress in a quarter of a century, and perspective: implication for learning and memory. Biol Pharm Bull. 2005;28:1342-54.

40. Lisman J, Schulman $\mathrm{H}$, Cline $\mathrm{H}$. The molecular basis of CaMKll function in synaptic and behavioural memory. Nat Rev Neurosci. 2002;3:175-90.

41. Porte $Y$, Buhot MC, Mons NE. Spatial memory in the Morris water maze and activation of cyclic AMP response element-binding (CREB) protein within the mouse hippocampus. Learn Mem. 2008;15:885-94.

42. Brenes O, Giachello CN, Corradi AM, Ghirardi M, Montarolo PG. Synapsin knockdown is associated with decreased neurite outgrowth, functional synaptogenesis impairment, and fast high-frequency neurotransmitter release. J Neurosci Res. 2015;93:1492-506.

43. Zhong $L$, Cherry $T$, Bies CE, Florence MA, Gerges NZ. Neurogranin enhances synaptic strength through its interaction with calmodulin. EMBO J. 2009:28:3027-39.

44. Steiner J, Gos T, Bogerts B, Bielau H, Drexhage HA, Bernstein HG. Possible impact of microglial cells and the monocyte-macrophage system on suicidal behavior. CNS Neurol Disord Drug Targets. 2013;12:971-9. 
45. Riazi K, Galic MA, Kentner AC, Reid AY, Sharkey KA, Pittman QJ. Microglia-dependent alteration of glutamatergic synaptic transmission and plasticity in the hippocampus during peripheral inflammation. J Neurosci. 2015;35:4942-52.

46. Dreyer EB, Kaiser PK, Offermann JT, Lipton SA. HIV-1 coat protein neurotoxicity prevented by calcium channel antagonists. Science. 1990; 248:364-7.

47. Wallace DR. HIV neurotoxicity: potential therapeutic interventions. J Biomed Biotechnol. 2006;2006:65741.

48. Li ST, Matsushita M, Moriwaki A, Saheki Y, Lu YF, Tomizawa K, Wu HY, Terada H, Matsui H. HIV-1 Tat inhibits long-term potentiation and attenuates spatial learning [corrected]. Ann Neurol. 2004;55:362-71.

49. Saiyed ZM, Gandhi N, Agudelo M, Napuri J, Samikkannu T, Reddy PV, Khatavkar P, Yndart A, Saxena SK, Nair MP. HIV-1 Tat upregulates expression of histone deacetylase-2 (HDAC2) in human neurons: implication for HIVassociated neurocognitive disorder (HAND). Neurochem Int. 2011;58:656-64.

50. Bellizzi MJ, Lu SM, Masliah E, Gelbard HA. Synaptic activity becomes excitotoxic in neurons exposed to elevated levels of platelet-activating factor. J Clin Invest. 2005;115:3185-92.

51. Yan X, Weng HR. Endogenous interleukin-1 beta in neuropathic rats enhances glutamate release from the primary afferents in the spinal dorsal horn through coupling with presynaptic N-methyl-D-aspartic acid receptors. J Biol Chem. 2013;288:30544-57.

52. Olmos G, Llado J. Tumor necrosis factor alpha: a link between neuroinflammation and excitotoxicity. Mediat Inflamm. 2014;2014:861231.

53. Marchetti L, Klein M, Schlett K, Pfizenmaier K, Eisel UL. Tumor necrosis factor (TNF)-mediated neuroprotection against glutamate-induced excitotoxicity is enhanced by N-methyl-D-aspartate receptor activation. Essential role of a TNF receptor 2-mediated phosphatidylinositol 3-kinase-dependent NF-kappa B pathway. J Biol Chem. 2004;279:32869-81.

54. Belarbi K, Jopson T, Tweedie D, Arellano C, Luo W, Greig NH, Rosi S. TNF-alpha protein synthesis inhibitor restores neuronal function and reverses cognitive deficits induced by chronic neuroinflammation. J Neuroinflammation. 2012;9:23.

55. Giovannelli A, Limatola C, Ragozzino D, Mileo AM, Ruggieri A, Ciotti MT, Mercanti D, Santoni A, Eusebi F. CXC chemokines interleukin-8 (IL-8) and growth-related gene product alpha (GROalpha) modulate Purkinje neuron activity in mouse cerebellum. J Neuroimmunol. 1998;92:122-32.

56. Xiong H, Boyle J, Winkelbauer M, Gorantla S, Zheng J, Ghorpade A, Persidsky Y, Carlson KA, Gendelman HE. Inhibition of long-term potentiation by interleukin-8: implications for human immunodeficiency virus-1associated dementia. J Neurosci Res. 2003;71:600-7.

57. Bellinger FP, Madamba S, Siggins GR. Interleukin 1 beta inhibits synaptic strength and long-term potentiation in the rat CA1 hippocampus. Brain Res. 1993:628:227-34.

58. Ellis R, Langford D, Masliah E. HIV and antiretroviral therapy in the brain: neuronal injury and repair. Nat Rev Neurosci. 2007:8:33-44.

\section{Ready to submit your research? Choose BMC and benefit from:}

- fast, convenient online submission

- thorough peer review by experienced researchers in your field

- rapid publication on acceptance

- support for research data, including large and complex data types

- gold Open Access which fosters wider collaboration and increased citations

- maximum visibility for your research: over $100 \mathrm{M}$ website views per year

At BMC, research is always in progress.

Learn more biomedcentral.com/submissions 